\title{
Hygrothermal Behaviour of Ventilation Cavities in Highly Insulated Envelopes
}

\author{
Klaus Viljanen ${ }^{1,2^{*}}$, Xiaosh $u$ Lü $^{1,3,4,5}$, and Jari Puttonen ${ }^{1}$ \\ ${ }^{1}$ Department of Civil Engineering, Aalto University, Finland \\ ${ }^{2}$ Ramboll Finland Oy, Finland \\ ${ }^{3}$ Department of Electrical Engineering and Energy Technology, University of Vaasa, Finland \\ ${ }^{4}$ Department College of Construction Engineering, Jilin University, China \\ ${ }^{5}$ Key Laboratory of Ministry of Land and Resources on Complicated Conditions Drilling Technology, China
}

\begin{abstract}
This article presents long-term experimental studies on the moisture safety in the ventilation cavities of highly insulated (HI) structures. The tested HI-walls had thermal transmittances of 0.11-0.13 $\mathrm{W} / \mathrm{m}^{2} \mathrm{~K}$. A wall with a thermal transmittance of $0.23 \mathrm{~W} / \mathrm{m}^{2} \mathrm{~K}$ represented the baseline wall in the test. In addition to walls, an HI-roof of a newly built house with a U-value of $0.08 \mathrm{~W} / \mathrm{m}^{2} \mathrm{~K}$ was measured. The results indicate that, in the ventilation cavity, the relative humidity of an HI-wall exceeds $1-7 \%$ of the humidity measured from the baseline wall during winter, which coincides with the $0.4-1.5^{\circ} \mathrm{C}$ lower temperatures observed in the HI-walls. The mold risk in the ventilation cavities of the walls is low, as the value of the mold index (MI) remains below one, which indicates small amounts of microscopic mold only on surfaces. However, at the bottom of the cavity, the MI value reaches 1.4 due to lower temperatures. In the HI-roof, the MI values are between 1.0 and 2.0 in the middle of the cavity in winter. The reasons for the higher mold risk of the roof are the humid weather, the built-in moisture of the roof and the low heat flux from inside. The study confirms that, in the future, warmer weather and increased humidity can increase moisture risks in the ventilation cavities. The results support the use of materials that are more resistant to mold in the outer parts of structures.
\end{abstract}

\section{Introduction}

Modern buildings have been adapted to the global endeavor to improve the energy efficiency in all sectors. Today, the thermal transmittances of external walls in Finland are commonly at a level of $0.12 \mathrm{~W} / \mathrm{m}^{2} \mathrm{~K}$, and the values can be even lower in roofs, like $0.08 \mathrm{~W} / \mathrm{m}^{2} \mathrm{~K}$. The typical thicknesses of mineral wool layers in walls and roofs are $300 \mathrm{~mm}$ and $500 \mathrm{~mm}$, respectively.

The research on the hygrothermal behavior and moisture safety of the highly insulated (HI) structures has focused mainly on the insulation space of the structures [1-7]. Due to the influence of the temperature distribution across the external structure on the hygric behavior, the performance is usually evaluated at the colder outer parts of the structure, excluding the ventilation cavity from the analysis [1-7]. The drying ability of the built-in moisture has been addressed by [1$5]$ and the effect of climate change by $[2,5]$. Only one of these studies is mainly based on experimental research methods [4].

In the cavity, mold damage might develop due to improper behavior, such as a low ventilation rate in the cavity or a high water vapor diffusion rate through the envelope structure. This might decrease the indoor air quality and raise health issues if compounds related to mold transfer into the indoor air through air leakages. An earlier study indicated that mold growth and humidity inside the structure increased the total volatile organic compound (TVOC) concentrations indoors even when the pressure difference between indoor and outdoor was low [8]. This supports the need to study the cavity conditions, as the leakage air can enter the building from the cavity.

Ojanen showed that cavity surfaces in ventilated HI-structures are close to outdoor conditions, which is typical for the surfaces of an unheated storage building [9]. He estimated that in these conditions, the material surfaces might encounter slight mold growth, but no structural damage would develop. Ojanen added that the modern buildings function well if the built-in moisture and indoor moisture are at reasonable levels with respect to the cavity ventilation. He also simulated the mold growth potential at the inner surface of the ventilation cavity in current Finnish weather conditions. The risk of mold formation on the wind barrier surface was reported to be identical with low energy and normal buildings and distinctly lower for an unheated building. He concluded that cold temperatures and a lack of moisture loads improve the performance of the unheated buildings. These simulations did not include the façade and the cavity.

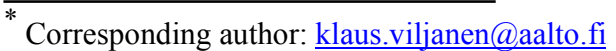


Based on the literature review, this study expands the research of moisture safety in HI-structures into the ventilation cavity. The study is comprised of long-term experimental tests conducted in Finland. The decision to use the experimental research method is supported by the fact that comprehensive simulation of the ventilated structure, including the propagation of hygrothermal conditions along the flow path, is a difficult task even today. The tests include four different wall structures and one roof structure. The evaluation of the structures is based on the hygrothermal conditions measured from ventilation cavities, calculated mold index (MI) levels and measured ventilation characteristics. The effect of climate change on the moisture safety of the cavity is addressed with a simplified method.

\section{Materials and Methods}

The hygrothermal conditions in the ventilation cavity of an external structure are determined by the interaction between heat and moisture transfer phenomena. Thermal conditions in the cavity are affected by outdoor weather conditions and indoor climate. The weather conditions include outdoor temperature and both shortwave and longwave radiation. In addition to heat conduction through the structure, heat is transferred inside the structure by convective flow generated by the cavity ventilation. The insulation level of the structure along with the temperature boundary conditions affect the conductive heat flux through the structure, which may influence the temperature in the cavity (see e.g. [10]).

Moisture conditions in the cavity are affected by the same factors that influence thermal conditions. In addition, moisture moves toward the cavity from indoors mainly by diffusion and from outdoors mainly by convection. Finally, the hygroscopic buffering of the materials next to the cavity influence moisture conditions in the cavity air. Based on these physical factors, two experiments were arranged to study the hygrothermal behavior of the ventilation cavity in different HI external structures.

The first test was comprised of four test walls in laboratory facilities at Aalto University in Southern Finland. Three of the test walls were HI-walls, and the fourth was a baseline (BL) wall. The insulation material was stone wool in the HI1- and BL-walls, glass wool in the HI2-wall and polyurethane (PU) foam in the HI3wall. The HI2-wall included a gypsum board behind the wind barrier insulation board, and the BL-wall had a gypsum board as the wind barrier layer. Walls HI1, HI2 and $\mathrm{BL}$ were vapor open toward the ventilation cavity; the $\mathrm{Sd}$ values for the mineral wool coatings and the gypsum boards were below $0.1 \mathrm{~m}$. Wall HI3 had aluminum-coated insulation boards and therefore represented a uniformly vapor-tight structure. Due to the aluminum coating, thermal radiation in the HI3-wall between the wind barrier surface and the inside surface of the cladding was less than in the other structures. The measured sorption and vapor diffusion properties of the mineral wool products and the gypsum boards are presented in [4]. The hygroscopic equilibrium moisture content of the wind barrier gypsum board is roughly eight times higher compared to mineral wool products at relative humidity $(\mathrm{RH}) 70-98 \%$. In addition, the moisture content of glass wool is two to nine times higher in $\mathrm{RH}$ $85-98 \%$ compared to stone wool. The HI3-wall had next to zero hygroscopic capacity at the wind barrier layer, which was the least of all the walls. The HI1- and BLwalls had a $0.2 \mathrm{~mm}$ thick polyethylene (PE) membrane as the vapor barrier. The HI2-wall included a vapor retarder made of polyamide (PA) foil. The vapor retarder had an RH-dependent Sd value between 0.77-26.8 m, where the highest $\mathrm{Sd}$ value corresponds to $26 \%$ - $\mathrm{RH}$ and the lowest value corresponds to $79 \%$ - RH [11].

The walls were set up in a test hut and were exposed to outdoor weather (Fig. 1). The indoor temperature and RH were adjusted with thermo- and hygrostats. The test house had no eaves; however, the ventilation flashing near point $\mathrm{C}$ might have affected the rainfall on the façade to a small extent. The cladding material was a $21 \times 120 \mathrm{~mm}^{2}$ sized wood board. The boards were painted dark grey with oil-based acrylate paint. The thickness of the ventilation cavity was $22 \mathrm{~mm}$ in every wall, which is typical for Finnish ventilated external wall structures. The cavity inlet was shut, and additional insulation was set on the cladding during a period of 5.3-16.7.2018, the impact of which is not assessed in this paper.

Measurements were set up in the wall cavities, in the room and in outdoor air according to Fig. 1. The measurements of temperature and $\mathrm{RH}$ were set at the middle height of the cavities; in addition, the HI1-wall measurements were made in the bottom and upper parts of the cavity. The measurement period for the temperature and humidity was 9.6.2017-30.12.2019. The measurements started when the test structures were complete. In the HI1-cavity, air velocity was monitored with a hot wire anemometer, and the air flow direction was monitored with a pressure difference measurement (Fig. 1). The moisture content (MC) of the cladding was monitored at the end of the study by measuring the electrical resistance of the wood. This resulted in the maximum $\mathrm{MC}$ at the measuring depth of $0-10 \mathrm{~mm}$. Solar radiation and precipitation were measured according to Fig. 1. The cladding boards were removed after the test for a visual inspection of the cavity surfaces.

The other test was made for the pitched roof of a newly built dwelling house in Helsinki. The building is in a windy location near the sea. The HI-roof with black bitumen roofing included a $100 \mathrm{~mm}$ thick ventilation cavity and $20 \mathrm{~mm}$ thick ventilation gaps at the eaves (Fig. 1). This ventilation setup in the roof is commonly used in Finland. The total insulation thickness was 500 $\mathrm{mm}$. The roof had the same vapor retarder and insulation material as the HI2-wall. Measurements were set up in one air cavity in the roof according to Fig. 1 before finishing the structure. Temperature and $\mathrm{RH}$ were measured at three points in the cavity. In addition, air velocity was measured at one point similar to the walltest. The measurement period was 8.9.2017-28.12.2019. 
Test walls, horizontal cut:

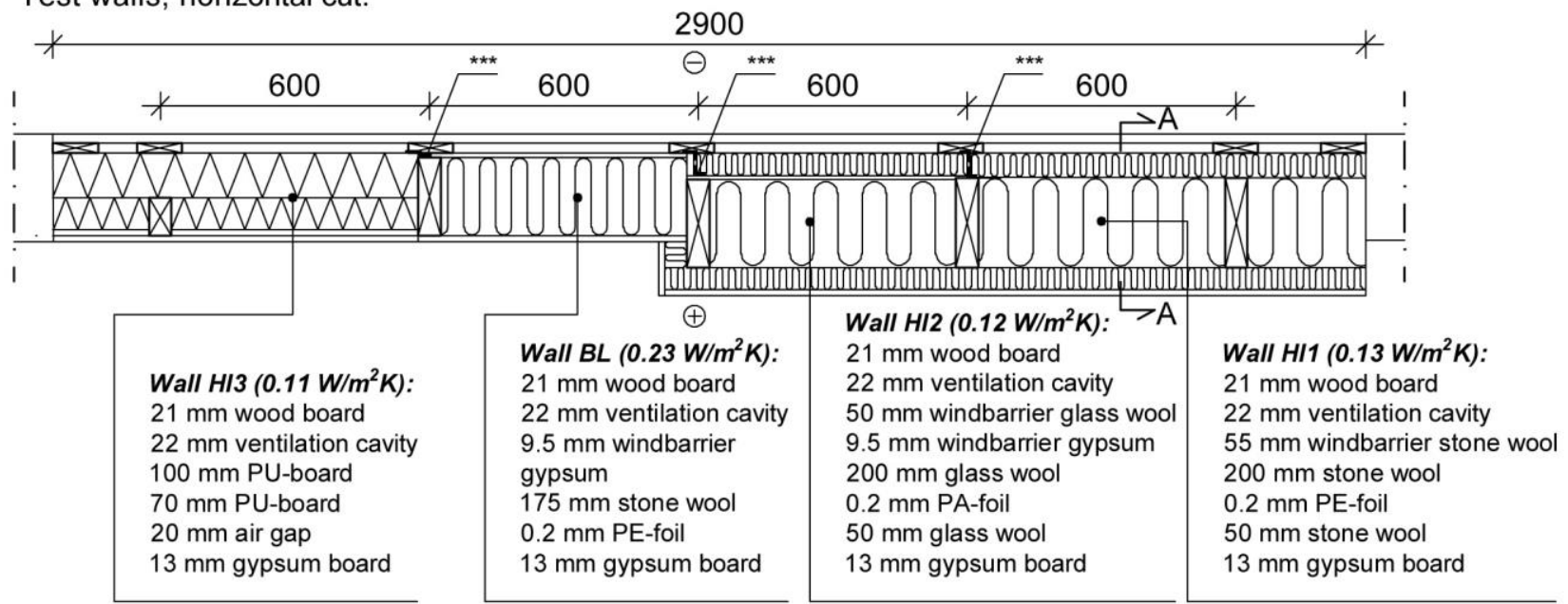

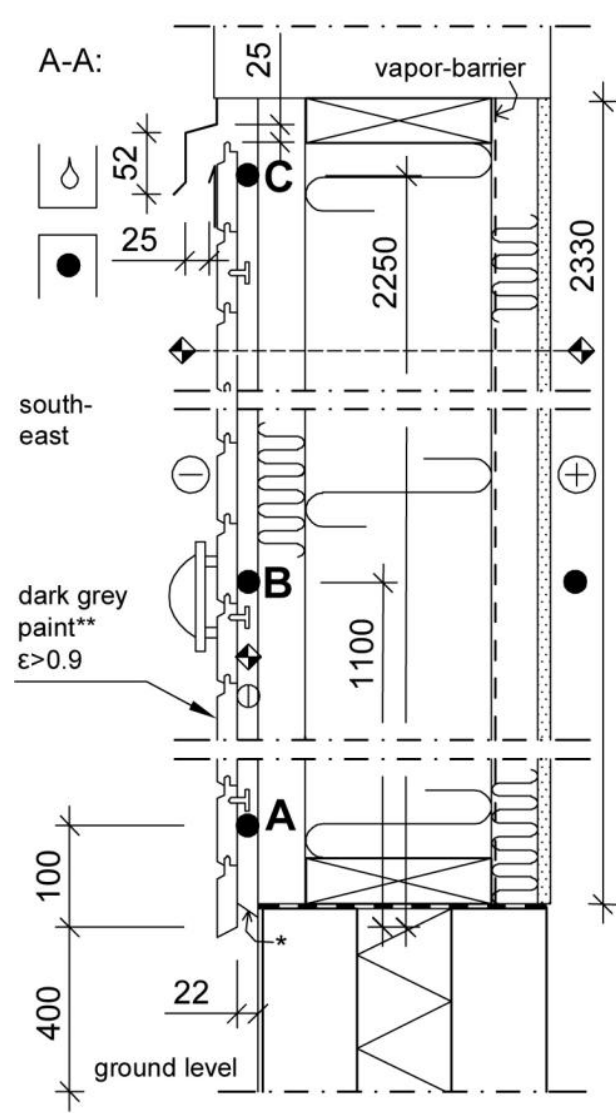

Test roof, vertical cut:

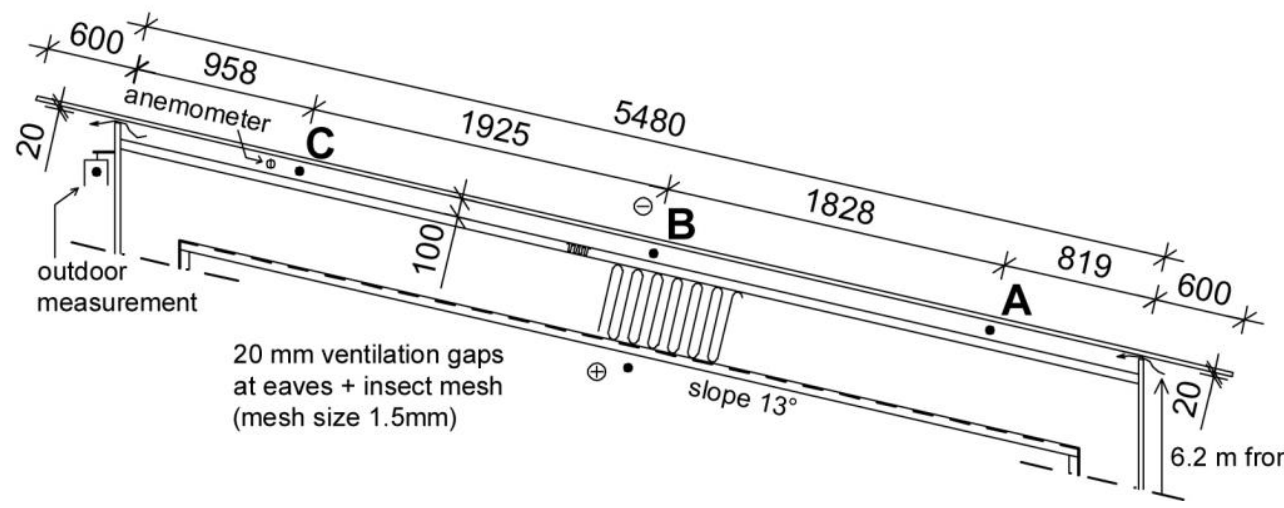

Fig. 1. Test setups in the wall and roof tests. temperature and $\mathrm{RH}$ (Vaisala HMP44: $\mathrm{RH} \pm 2 \%$ at $0 . .90 \%-\mathrm{RH}, \pm 3 \%$ at $90 . .100 \%-\mathrm{RH}$ $\mathrm{T} \pm 0.3 . .0 .4^{\circ} \mathrm{C}$ ) probes located in cavities of test walls at the height of $110 \mathrm{~cm}$ from the bottom of the cladding; in wall HI1 additional heights $10 \mathrm{~cm}$ and $225 \mathrm{~cm}$; in wall $\mathrm{HI} 3$ additional heights $10 \mathrm{~cm}$ and $225 \mathrm{~cm}$ with PT100-sensors (4-wire, class-B $\pm 0.3^{\circ} \mathrm{C}$ ); measurements with HMP44 in roof, see vertical cut of roof below; indoor and outdoor climates in both tests measured with HMP44.

(1) air velocity measurement with hot wire anemometer (Lutron AM-4214SD) in wall HI and in roof; accuracy $5 \%+0.1 \mathrm{~m} / \mathrm{s}$ and resolution $0.01 \mathrm{~m} / \mathrm{s}$ at $0.2-5 \mathrm{~m} / \mathrm{s}$; minimum temperature for operation $0^{\circ} \mathrm{C}$.

shortwave radiation measurement $\left(\mathrm{W} / \mathrm{m}^{2}\right)$ with pyranometer (Kipp\&Zonen CMP3) at the middle of the facade; spectral range $300-2800 \mathrm{~nm}$.

\&f cladding MC measurement from three heights in all walls (Scanntronik Material moisture Gigamodule and Thermofox: range $6-90$ weight- $\%$ for wood, resolution 0.1 weight-\%).

$\checkmark$ measurement of precipitation (Vaisala RG13 located on the above roof).

$\Delta$ measurement of air flow direction in the cavity (pressure difference, Beck 985A, \pm 25 $\mathrm{Pa}$ ) in wall $\mathrm{HI} 1$; measured with $4 \mathrm{~mm}$ thick metal pipes directed up and down:

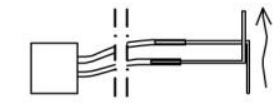

$$
\text { dp-logger cavity }
$$

$\rightarrow$ pressure difference measurement across the walls (Beck 984Q, $\pm 50 \mathrm{~Pa}$ )

*mouse list with $5 \mathrm{~mm}$ gaps:

${ }^{* *}$ NCS-standard color S 7502-B

***vapor-tight sealing between walls

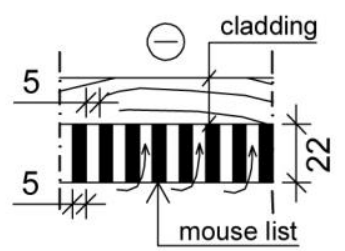

Roof $\left(0.08 \mathrm{~W} / \mathrm{m}^{2} \mathrm{~K}\right)$ :

$6 \mathrm{~mm}$ double bitumen felt $18 \mathrm{~mm}$ plywood

$100 \mathrm{~mm}$ ventilation cavity $50 \mathrm{~mm}$ windbarrier glasswool (continuous)

$400 \mathrm{~mm}$ glasswool + wooden beams $k 600$

$0.2 \mathrm{~mm}$ PA-foil

$50 \mathrm{~mm}$ glasswool + joists $\mathrm{k} 600$

$13 \mathrm{~mm}$ gypsum board

south, approx. $50 \mathrm{~m}$ from Gulf of Finland 
Window and door installations were made from 17.22.9.2017, and the heating system (water-based underfloor heating) was turned on in October 2017. The residents moved in on 5.9.2018, and the ventilation was turned on simultaneously. The ventilation gap near point A was closed and additional insulation was set on the roof during a period of 6.3.-18.3.2018, the impact of which is not assessed in this paper. The air leakage rate of the building envelope was measured to be 0.19 $\mathrm{m}^{3} / \mathrm{hm}^{2}$ at a $50 \mathrm{~Pa}$ pressure difference between indoor and outdoor air.

\section{Results}

\subsection{Boundary conditions during the tests}

Indoor humidity might influence the moisture conditions in the cavity; therefore, the indoor air was humidified in the wall test to an average level of $47.4 \%-\mathrm{RH}$ (Fig. 2). Fig. 2 and most of the figures in Section 3 represent averaged values, as mentioned in each caption. The average indoor temperature was $21.3^{\circ} \mathrm{C}$ during the test. The average moisture excess between indoor and outdoor air was $1.7 \mathrm{~g} / \mathrm{m}^{3}$, but the excess was increasing toward the end of the test. The pressure difference across the walls was below $1 \mathrm{~Pa}$ for most of the time. Therefore, the moisture transfer from indoor air toward the cavity was mainly due to water vapor diffusion.

In the roof study, the indoor RH had values over $60 \%$ at the beginning of the test (Fig. 2). The average indoor RH was $46.3 \%$, and the average indoor temperature was $18.5^{\circ} \mathrm{C}$. The average moisture excess between indoor and outdoor air was $0.7 \mathrm{~g} / \mathrm{m}^{3}$. During the last 10 months of the test, the absolute humidity (AH) difference between indoor and outdoor varied around zero.

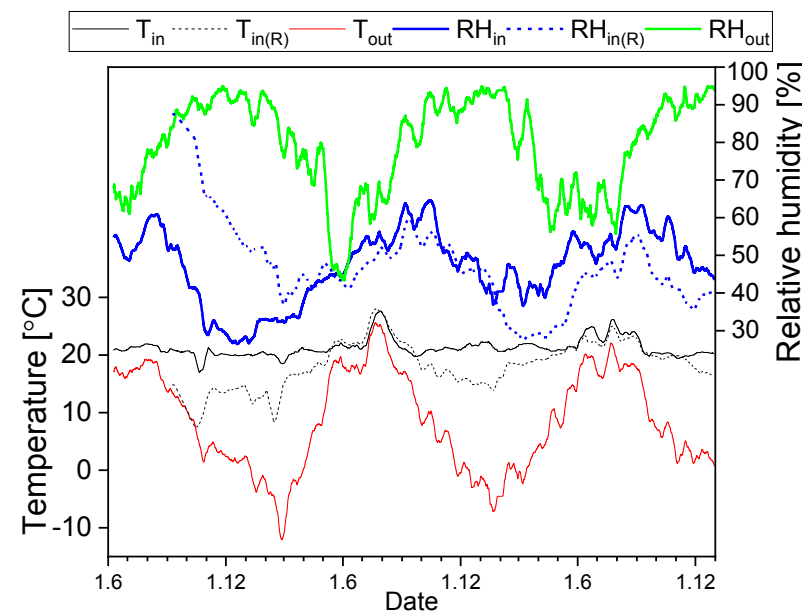

Fig. 2. Measured boundary conditions during the tests (two weeks' avg.). Measured values in the roof study are denoted by R.

\subsection{Air flow inside the cavity}

The air flow rates were evaluated in the cavities of the HI1-wall and the HI-roof based on the measured air velocities in the cavities. The calculation method assumed a fully developed laminar flow and parabolic velocity profile in the cavity; therefore, the ratio of average velocity to measured maximum velocity is 0.67 $[12,13]$. The air change rate was calculated with the formula shown in Fig. 3.

During summer, the velocity of the air in the HI1cavity was $0.3 \mathrm{~m} / \mathrm{s}$ on average. In August, this started to decline steadily until October to a level of $0.038 \mathrm{~m} / \mathrm{s}$ on average (Fig. 3). The corresponding air change rates were $310 \mathrm{l} / \mathrm{h}$ and 40 1/h (Fig. 3). In Ref. [13], ventilation rates of $100-10001 / \mathrm{h}$ are presented for a similar type of façade with a cavity depth of $40 \mathrm{~mm}$ and slightly more open outlet. In summer, the maximum velocity in the HI1-cavity during the daytime was $0.9 \mathrm{~m} / \mathrm{s}$, and the lowest velocity was $0.06 \mathrm{~m} / \mathrm{s}$ during the nighttime. In winter, the velocity varied between $0-0.15 \mathrm{~m} / \mathrm{s}$.

In the roof, the velocity changed according to the season; in summer, the two days' average velocity was $0.2-0.5 \mathrm{~m} / \mathrm{s}$, and in winter, the average was $0.1-0.3 \mathrm{~m} / \mathrm{s}$. The corresponding air change rates for the roof were 88 $220 \mathrm{l} / \mathrm{h}$ and $44-131 \mathrm{l} / \mathrm{h}$. The instantaneous changes in the cavity velocity were higher in the roof structure, which indicates that the wind influenced the cavity velocities more in this structure. This explains why the range of the velocity in the roof was not as dependent on the season as it was in the wall. In summer, the maximum velocity was $1 \mathrm{~m} / \mathrm{s}$, and the lowest velocity was $0 \mathrm{~m} / \mathrm{s}$.

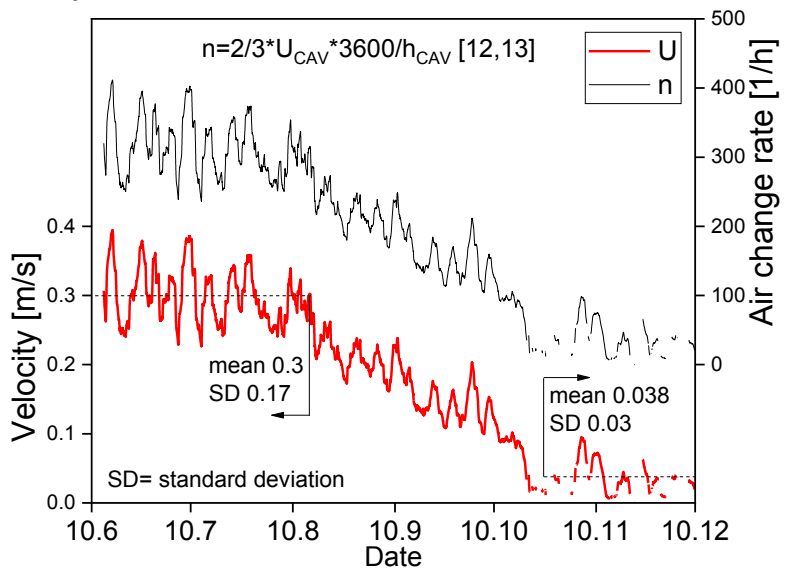

Fig. 3. Measured velocity in the cavity of the HI1-wall and calculated air change rate (two days' avg.) during 2017.

\subsection{Thermal behaviour of the cavities}

The measured thermal conditions in the ventilation cavities of the test walls were compared seasonally. In winter, the temperatures in the middle height of the ventilation cavities of the HI-walls were typically 0.4 $1.5^{\circ} \mathrm{C}$ lower compared to the BL-wall (Fig. 4). In midsummer, this temperature difference varied during the day. At night, the HI-temperatures were $0.5-1.5^{\circ} \mathrm{C}$ below the BL-wall temperatures, and by day, they were $1-5^{\circ} \mathrm{C}$ above. Thus, the higher U-value of the wall structure increased the cavity temperature during the night and decreased it when the façade was exposed to solar radiation (Fig. 5). Within the HI-walls, the HI3-wall had $1-2^{\circ} \mathrm{C}$ higher temperatures during solar radiation and, at most, $0.5^{\circ} \mathrm{C}$ lower temperatures during summer nights. These small differences with the HI3-wall compared to the other HI-walls may be related to the aluminum 
surface on the inside of the cavity, which decreased the radiation heat transfer between the aluminum surface and the cladding surface.

The temperature difference between point B of the wall or roof cavity and the outdoor air was dependent on the season; in winter, the temperatures in the cavities of the walls and the roof were typically $0-2^{\circ} \mathrm{C}$ and $0.2^{\circ} \mathrm{C}$ above outdoor level, respectively (Fig. 6). During summer, the cavity temperatures were $0-20^{\circ} \mathrm{C}$ above outdoor level (Fig. 5, Fig. 6). During the measurement period, the highest temperature was $53^{\circ} \mathrm{C}$ in the walls and $55^{\circ} \mathrm{C}$ in the roof in late summer when the outdoor temperature was $35^{\circ} \mathrm{C}$. The high temperatures were caused by the absorption of solar radiation into the dark colored cladding and roof surfaces.

In mid-summer in the middle of the day, the temperature along the airflow path in the HI1- and HI3walls and the roof increased toward the top of the walls and the upper eaves. When the outdoor temperature rose to $29^{\circ} \mathrm{C}$, the temperature at point $\mathrm{A}$ was $35^{\circ} \mathrm{C}$ in the walls and $40^{\circ} \mathrm{C}$ in the roof. The temperature at points $\mathrm{B}$ and $\mathrm{C}$ was usually $45-47^{\circ} \mathrm{C}$ in the walls and $49-53^{\circ} \mathrm{C}$ in the roof. The temperature varied similarly in the cavities of the HI1- and HI3-walls. In the roof, a temperature difference of $2-3^{\circ} \mathrm{C}$ was usually present between points $\mathrm{B}$ and $\mathrm{C}$. In winter, the same temperature distribution along the cavities was present in the HI1-wall and the roof, but the temperature difference between points A-C was below $1^{\circ} \mathrm{C}$. In the $\mathrm{HI} 3$-wall, the temperatures were more even with maximum variation around $0.3^{\circ} \mathrm{C}$, which may have arisen from the aluminum coating at the wind barrier surface.

Relating to the analysis in Section 3.2, a uniform temperature distribution in the cavity implies there is no airflow [14]. Therefore, the aforementioned temperature differences suggest that air flowed in both cavities throughout the year. However, the exact evaluation of the velocity of the airflow is not possible based on the temperature difference in the cavity, as the cavity is subjected to changing external conditions. The temperature variations along the cavities were affected by a cold inlet air, which decreased the cavity temperature at the bottom of the cavity. The temperature increase in the vertical direction of the cavity further indicated that the direction of the airflow is mostly from point $\mathrm{A}$ to point $\mathrm{C}$. This was supported by the pressure difference measurement in the HI1-cavity; the weekly average of the pressure difference in the HI1-cavity was 0.005-0.03 Pa during summer and close to zero during the cold season. During sunny days, the upward pressure difference developed four hours after the first solar radiation reached the façade and continued until the intensity of the solar radiation began to decrease. This suggests that during summer, the highest ventilation rates occur after the façade has warmed up. This was supported by the anemometer results.

\subsection{Hygric behaviour of the cavities}

The RH measured in the middle height of the ventilation cavity was compared between the HI-walls and the BL- wall (Fig. 7). In winter, RH was typically $1-7 \%$ higher in the HI-walls compared to the BL-wall. In summer, this difference remained only for the HI1-wall in which $\mathrm{RH}$ was $2-3 \%$ higher compared to the BL-wall; the RH values of the HI2- and HI3-walls were typically the same as or $1-2 \%$ below the $\mathrm{RH}$ values of the BL-wall.

RH was usually below outdoor level at the middle height of the cavities of all the studied structures, and the magnitude of the difference was dependent on the season and amount of solar radiation (Fig. 8). In winter, the RH levels were closest to the outdoor values, especially in the roof. During summer, RH was $12-20 \%$ below the outdoor level in the studied structures.

At the beginning of the measurements of the roof, the cavity RH level was $0-10 \%$ above the outdoor level. This was most likely connected to the built-in moisture in the roof and other structures in the building. The indoor RH was over $60 \%$ with an average value of $68 \%$ for almost three months after installing the windows and doors. This resulted from the moisture sources, such as the installation mortar used for floor tiles, and the humid and rainy outdoor weather before the installation. The ventilation started after the building was complete a year after the first measurements.

A similar comparison between $\mathrm{AH}$ in the cavity and outdoor $\mathrm{AH}$ revealed that the $\mathrm{AH}$ levels in the cavities were close to outdoor values during the cold

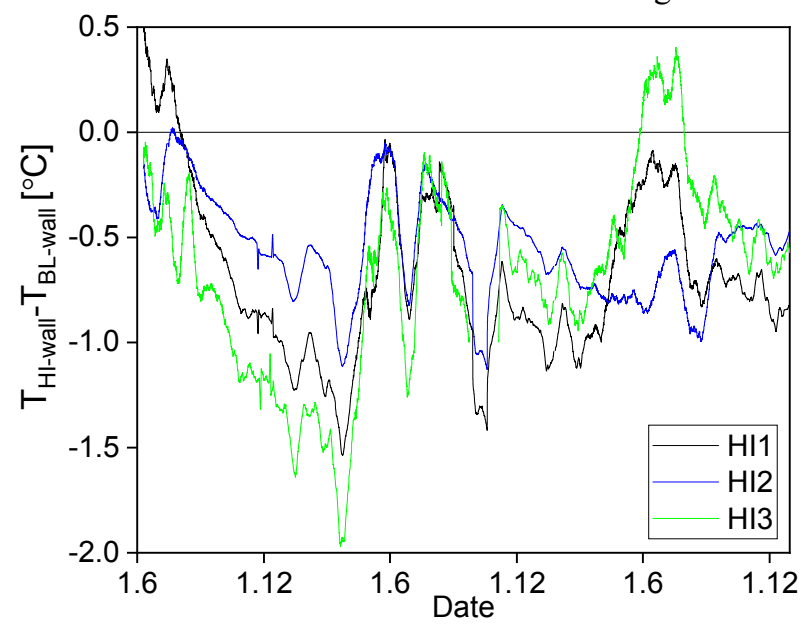

Fig. 4. Measured temperature difference between the HI-walls and the BL-wall (1-week avg.) at point B during 2017-2019.

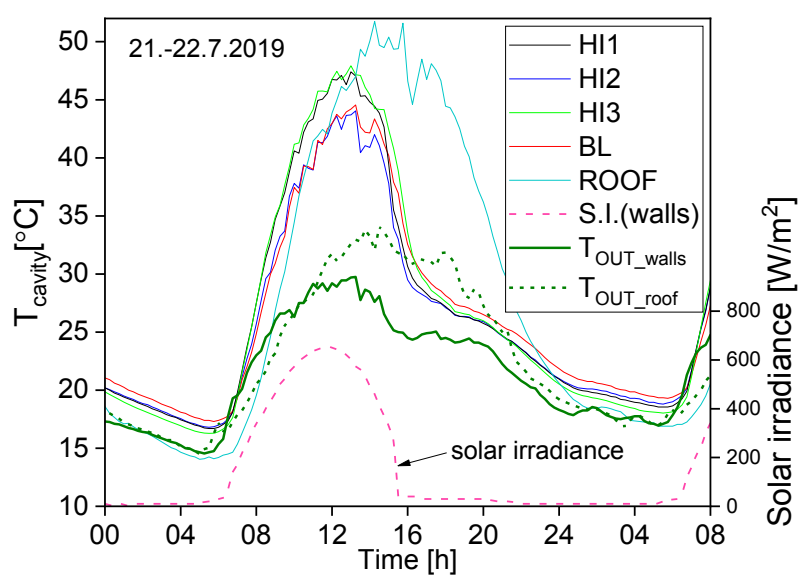

Fig. 5. Typical temperature development at the cavity at point $\mathrm{B}$, outdoor temperatures in both tests and solar irradiance in the wall test during a summer day. 


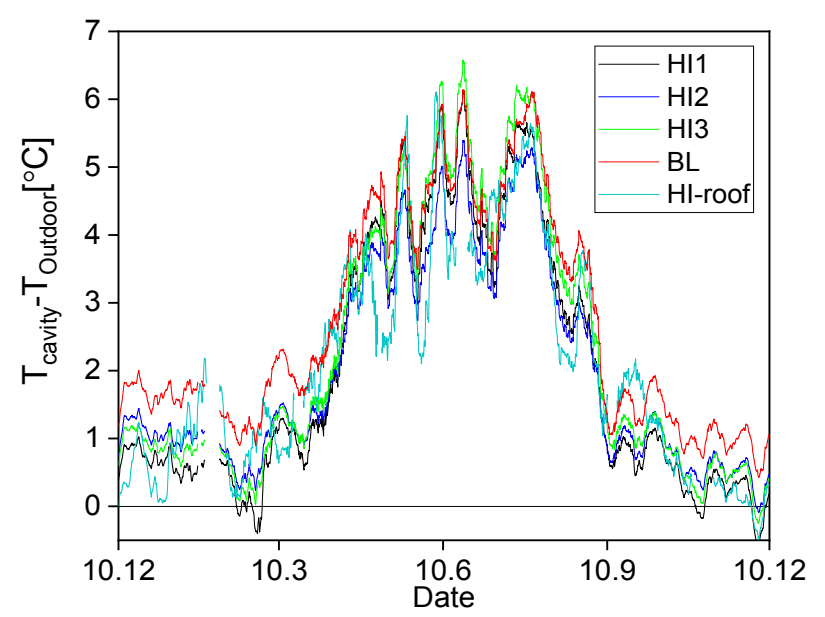

Fig. 6. Measured temperature difference between the ventilation cavity at point $\mathrm{B}$ and outdoor air (1-week avg.) during 2018-2019.

season. However, in the roof and in the BL-wall, AH was $0.1-0.2 \mathrm{~g} / \mathrm{m}^{3}$ above the outdoor values (Fig. 9). In summer, the highest difference of the cavity $\mathrm{AH}$ from the outdoor air AH was in the HI3-wall, and the lowest difference was in the HI1-wall. In the HI2-wall, the AH content was between that of the other walls; no sign of moisture accumulation in the cavity was found, although the structure had a vapor retarder instead of a barrier. In the BL-wall, the AH levels did not diverge from the other walls on an annual basis.

RH decreased toward the upper part of the ventilation cavity of the HI1-wall throughout the test period (Fig. 10), which most likely related to the convective heat transfer from outdoor air. The predominantly upward direction of the ventilation air decreases the temperature, especially in the lower parts of the cavity. In winter, the AH along the HI1-cavity varied typically $0.2-0.3 \mathrm{~g} / \mathrm{m}^{3}$ at the most, which supports the conclusion that the RH conditions in the cavity are determined mainly by heat transfer in the cavity. In summer, $\mathrm{AH}$ was $0-0.5 \mathrm{~g} / \mathrm{m}^{3}$ and $1 \mathrm{~g} / \mathrm{m}^{3}$ below outdoor values at points $\mathrm{B}$ and $\mathrm{C}$, respectively. At point $\mathrm{A}, \mathrm{AH}$ was mostly at the outdoor level.

In November through December 2019, the MC of the wood cladding typically varied between 10-22 weight- $\%$ in all walls at points $\mathrm{A}$ and $\mathrm{B}$ (Fig. 11). At point $\mathrm{C}$, the $\mathrm{MC}$ levels varied between $10-18$ weight- $\%$. The MC levels in the HI-walls diverged from the BLwall at points $\mathrm{A}$ and $\mathrm{B}$, where HI1- and HI2-walls had typically 1-4 weight- $\%$ higher MC compared to the BLwall. The HI3-wall usually had 1-3 weight-\% lower MC values than the BL-wall at point $\mathrm{A}$ and similar values at points $\mathrm{B}$ and $\mathrm{C}$. At point $\mathrm{C}$, the $\mathrm{MC}$ values of all walls were close to each other. However, the MC values in the HI3-wall deviated momentarily; at times, MC was 3 weight- $\%$ lower and sometimes 2 weight- $\%$ higher compared to the other walls.

The measured MC values in the cladding rose in two to five hours as much as 10 weight- $\%$ during rainy weather. The highest changes were measured at points $\mathrm{A}$ and $\mathrm{B}$. The rapid changes in MC levels (Fig. 11, Fig. 12) compared to earlier work [15] can be explained by the moisture measurement method. Most likely, the measured $\mathrm{MC}$ levels represent the $\mathrm{MC}$ at the inner surface of the cladding wood boards. The rapid increase in MC levels in Fig. 12 occurred in the middle of the three-day rainy period. This suggests that after dry weather periods, notable moisture accumulation in the cladding arises only after a few days of rainy weather when RH in the cavity exceeds $90 \%$. However, after a

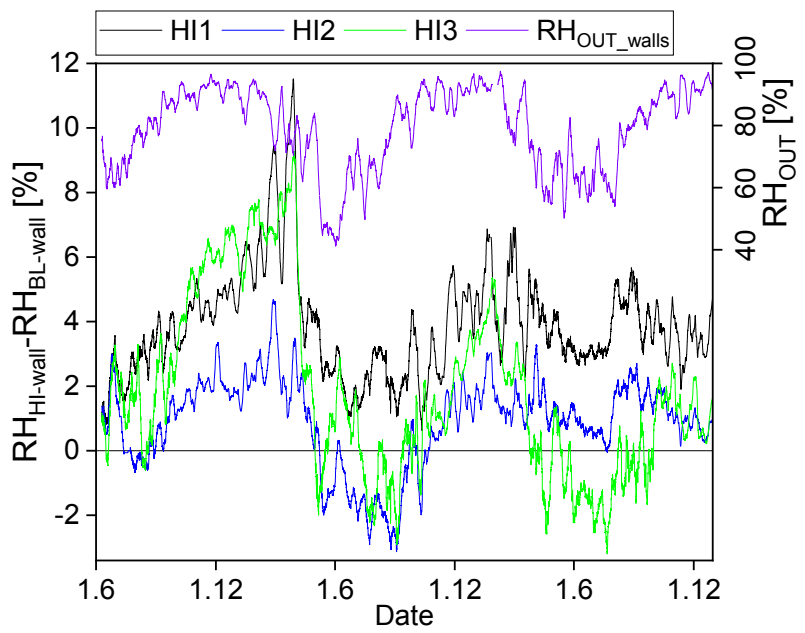

Fig. 7. Measured difference in RH between the HI-walls and the BL-wall cavities (1-week avg.) and outdoor RH (two weeks' avg.) during 2017-2019.

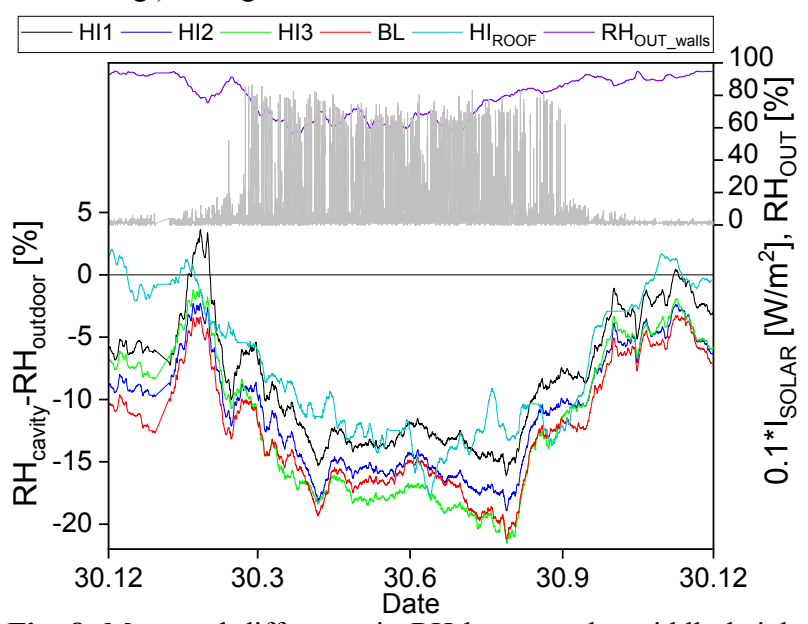

Fig. 8. Measured difference in RH between the middle height in the ventilation cavity and outdoor air (two weeks' avg.), solar irradiation and outdoor RH (two weeks' avg.) during 2018-2019.

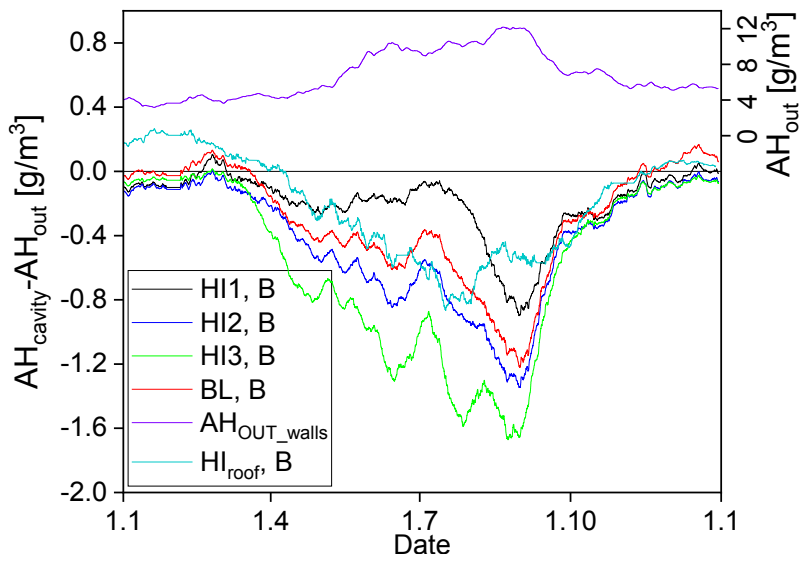

Fig. 9. Difference in $\mathrm{AH}$ between the middle height in the ventilation cavity and outdoor air (three weeks' avg.) and the outdoor AH (three weeks' avg.) during 2019. 
more humid weather period, cladding MC might rise a few hours after the beginning of rain, as the humidity in the cavity is already at a higher level. Generally, the hygroscopic surfaces in the cavity absorb and desorb moisture following the changes of outdoor conditions. Therefore, the measured $\mathrm{AH}$ levels in the cavities were momentarily above outdoor level either when outdoor humidity declined or after rainy periods. These results were similar for all walls.

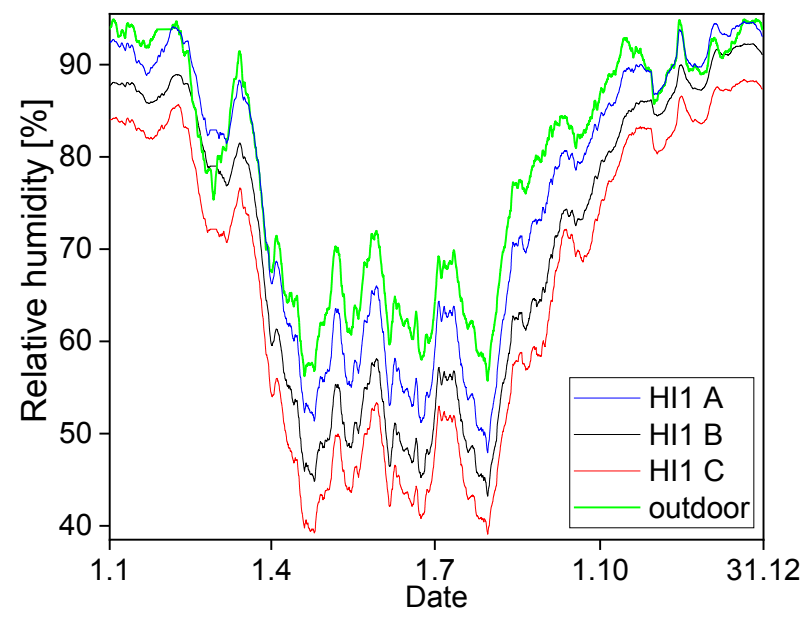

Fig. 10. RH along the ventilation cavity in the HI1-wall (two weeks' avg.) and in outdoor air (two weeks' avg.) during 2019.

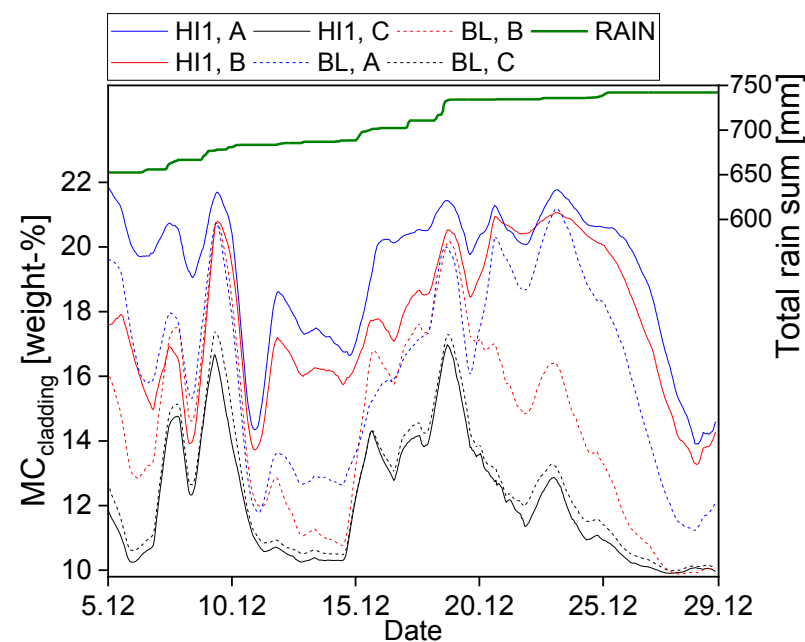

Fig. 11. Measured MC of the wood board cladding (six hours' avg.) in points A-C and progress of the annual rainfall in December 2019.

\subsection{Weather analysis and mold growth potential in the cavity}

The weather conditions during the experiments were evaluated regarding outdoor $\mathrm{RH}$ and precipitation (Fig. 13). These conditions were compared to the Finnish moisture reference year Jokioinen 2004 [16], which has suitable weather data for structures, where rain leakages are not considered. In addition, the measured weather was compared to the weather predicted in the future (Jokioinen A2 2050) [16]. The outdoor RH during the years 2017-2019 was at most 3-4\% below the reference years 2004 and 2050 in winter. The annual precipitation was highest during 2017 at the wall-test with $90-120 \mathrm{~mm}$ more precipitation compared to the reference years.

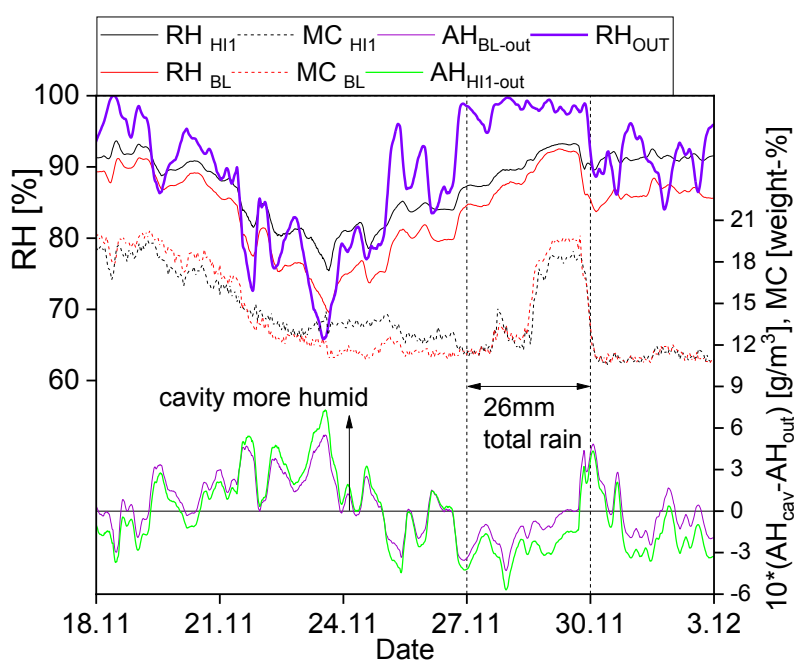

Fig. 12. Measured $\mathrm{MC}$ of the wood board cladding at point $\mathrm{B}$, $\mathrm{RH}$ in the cavity at point B and outdoor air (three hours' avg.), and $\mathrm{AH}$ difference between cavity point $\mathrm{B}$ and outdoor air (three hours' avg.).

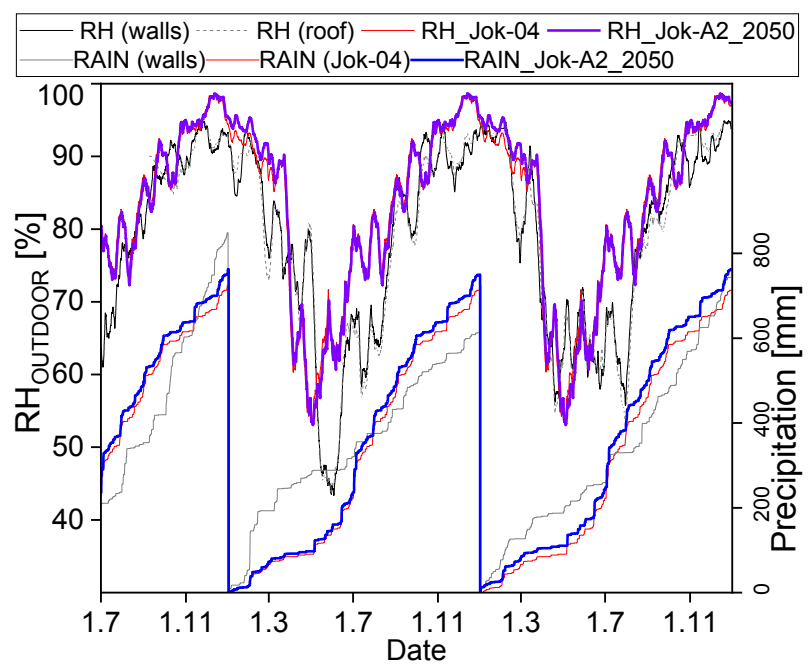

Fig. 13. Outdoor RH (two weeks' avg.) and precipitation during the experiments and according to moisture reference years 2004 and 2050 in Jokioinen [16].

During 2018-2019, the difference in the annual precipitation was much less; precipitation in the wall-test was $20 \mathrm{~mm}$ lower than in Jokioinen A2 2050-weather data. The weather comparison suggests that the weather during the experimental tests was relatively harsh with respect to the hygrothermal behavior of structures.

The quality of the hygrothermal performance of the examined ventilation cavities was evaluated by estimating the possibility for mold growth under the thermal and hygric conditions measured in the cavities. These conditions and the mold growth potential were also evaluated in a possible future climate; the conditions were developed from the measurement results presented in this paper and the estimated climate change. As the cavity temperature depends on the outdoor temperature, the measured temperatures in the roof and wall cavities were raised by the monthly values for the outdoor rise in temperature according to the A2 emission scenario [16]. This change in outdoor temperature is based on the measured weather during the period 1980-2009 in Jokioinen and the future weather in Jokioinen in 2050. 
The rise in outdoor temperature is higher in winter than in summer; on average, the temperature rise is $2^{\circ} \mathrm{C}$. The $\mathrm{RH}$ in the cavity was calculated with the saturation humidity according to the elevated cavity temperature. The $\mathrm{AH}$ in the cavity was determined by adding the measured $\mathrm{AH}$ in the cavity to the difference in outdoor $\mathrm{AH}$ between the measured climate and estimated future climate. This method was selected since the measured cavity $\mathrm{AH}$ depended on the outdoor $\mathrm{AH}$ and, especially in winter, it was at outdoor level. An example of the change in hygrothermal conditions in the roof cavity is presented in Fig. 14.

The Finnish mold growth model $[17,18]$ was selected to represent the mold growth potential in the cavity. MI values 1-6 correspond to small amounts of microscopic mold, distinct microscopic growth, growth visible to the naked eye, distinct growth visible to the naked eye, abundant growth visible to the naked eye and highly abundant mold growth, respectively. The sensitivity classes for both mold growth speed and maximum amount of mold are: 1 (very sensitive), 2 (sensitive), 3 (medium resistant) and 4 (resistant). Recession classes are: 1 (strong), 0.5 (significant), 0.25 (relatively low) and 0.1 (almost no decline). The mold growth potential was evaluated for the wood surfaces of the façade cladding and the roof plywood, for wind barrier surfaces (mineral wool coatings), for the aluminum surface in the HI3-wall and for the cardboard surface in the BL-wall. Most representative model parameters according to the cavity materials are presented in Table 1. However, due to low MI values in general, class $1 / 1 / 0.5$ was used in many cases.

The MI-values at point $\mathrm{B}$ in the wall cavity remained distinctly below 0.5 with the maximum value 0.36 found in the HI1-wall during the third winter (Fig. 15). At point $\mathrm{A}$ in the HI1-wall, the MI value increased to 1.4 at the end of the test; this was expected since the measurement point was located only $10 \mathrm{~cm}$ from the ventilation inlet. The the hygrothermal conditions at this point were closest to outdoor conditions, where the MI value rose during the test period near the maximum level of six. The MI values in the future climate stayed below one except for point A in the HI1-wall (Fig. 16). Here, the index value rose to 1.6 and 5.4 , depending on the sensitivity for mold growth. Overall, the hygrothermal conditions in the ventilated wall cavities diverged greatly from outdoor climate and were unfavourable to mold growth.

The MI-values in the HI-roof in the measured climate were highest at point $\mathrm{B}$, where the MI increased to one and two during the first winter, depending on the sensitivity classes (Fig. 17). In this type of roof, the more sensitive class 1 is applicable to, for example, sawn timber parts, which were not used in the current roof. The MI remained below one at point $\mathrm{C}$ and below 0.5 at point A. Therefore, the HI-roof behaved differently than the HI-walls, as the most critical point along the air-flow path was not near the ventilation inlet area.

In the roof structure, the future climate increased the MI-values; at points $\mathrm{B}$ and $\mathrm{C}$ with the most sensitive model parameters, MI-values over four developed during the time period (Fig. 18). Less sensitive material parameters gave MI-values of 1.4 at point B and 1.1 at point $\mathrm{C}$. The results suggest that there is an increased possibility for mold growth in ventilated HI-roof structures in the future climate.

The cladding wood boards were removed after the test on 23.1.2020. Seen from the outside, mold growth was observed on the left vertical cavity batten in the HI1-cavity and in the batten between the BL-wall and HI3-wall. In both locations, the growth was limited to a height of 0-450 $\mathrm{mm}$ from the bottom of the façade. Mold growth was not observed on any weather barrier boards or on the inner surface of the cladding. The cavity battens were sawn timber, and the cladding wood boards were fine sawn timber; therefore, the cavity battens were more sensitive to mold growth. The weather barrier gypsum in the BL-wall had the same sensitivity for mold growth as the cavity battens. The mold growth observed only in cavity battens suggests the heat flux through the structures improved the conditions on the weather barrier surfaces.

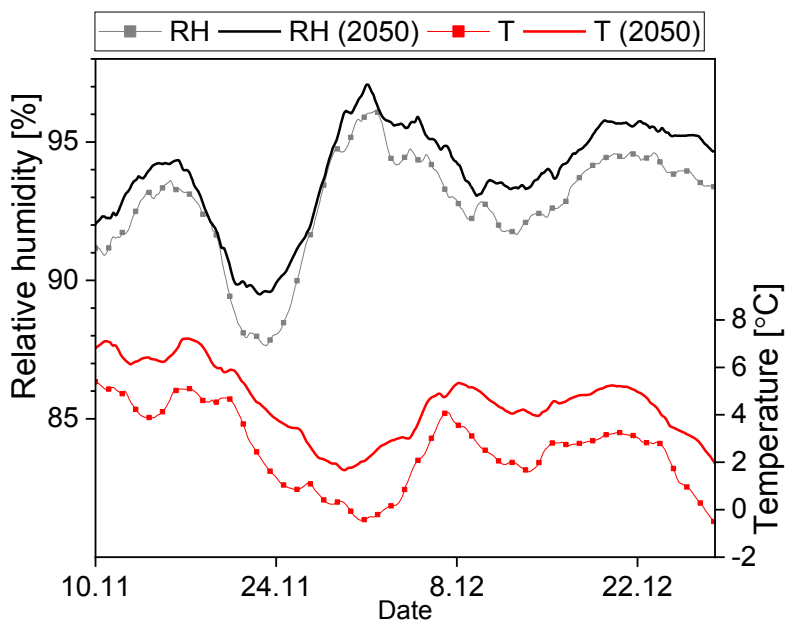

Fig. 14. An example of the measured hygrothermal conditions in the roof cavity at point B (1-week avg.) in winter 2019 and estimated cavity conditions in the year 2050 based on the estimated climate change [16].

Table 1. MI model parameters (growth speed/maximum amount of mold/recession classes) according to [17]; cardboard according to [19].

\begin{tabular}{|c|c|c|}
\hline Structure & $\begin{array}{c}\text { Outer surface of } \\
\text { wind barrier }\end{array}$ & $\begin{array}{c}\text { Inner surface of } \\
\text { cladding }\end{array}$ \\
\hline HI1 & $\begin{array}{c}\text { white HDPE-coating; } \\
3 / 3 / 0.1\end{array}$ & wood board; $2 / 2 / 0.25$ \\
\hline HI2 & $\begin{array}{c}\text { yellow glass fiber- } \\
\text { based coating; } 3 / 3 / 0.1\end{array}$ & wood board; $2 / 2 / 0.25$ \\
\hline HI3 & aluminum foil; $4 / 4 / 0$ & wood board; $2 / 2 / 0.25$ \\
\hline BL & cardboard; $1 / 1 / 0.5$ & wood board; $2 / 2 / 0.25$ \\
\hline roof & $\begin{array}{c}\text { yellow glass fiber- } \\
\text { based coating; } 3 / 3 / 0.1\end{array}$ & plywood; $2 / 2 / 0.25$ \\
\hline
\end{tabular}

\section{Discussion and Conclusions}

This paper presents the results from two experimental arrangements of the hygrothermal behaviour of 
ventilation cavities in different $\mathrm{HI}$ external structures. The first test

walls, (1) 1/1/0.5, (2) 2/2/0.25, measured climate

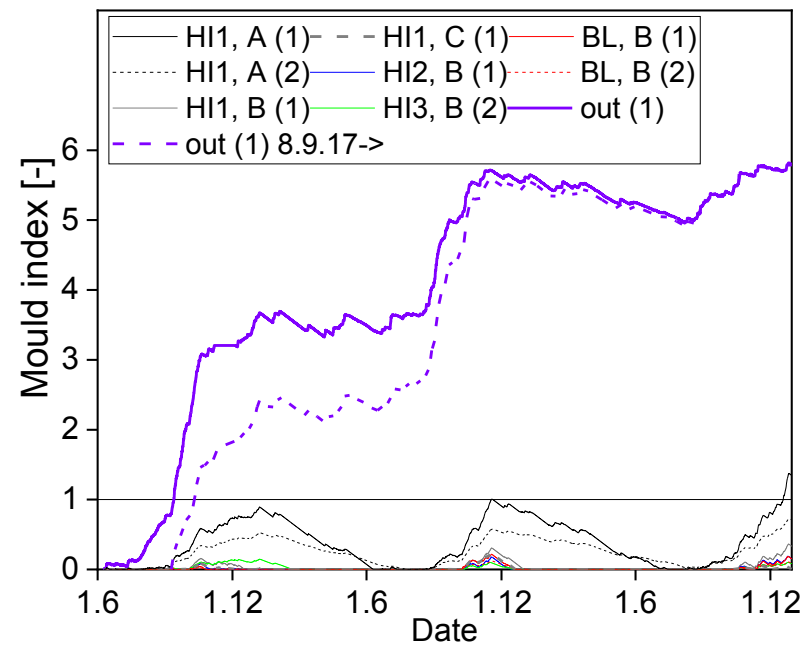

Fig. 15. Calculated MI values in the examined test walls and in the Espoo climate. Mold model parameters are denoted in brackets.

walls, (1) $1 / 1 / 0.5$, (2) 2/2/0.25, A2_2050 -climate

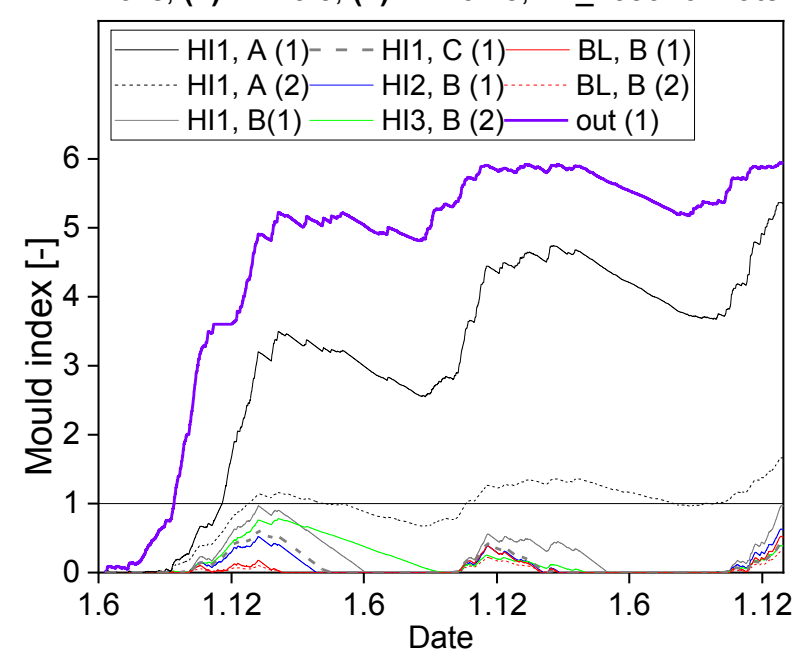

Fig. 16. Calculated MI values in the examined test walls and in Espoo climate with estimated conditions in the year 2050 based on [16].

series was conducted in a laboratory with real outdoor weather conditions, and the second arrangement was carried out in a newly built dwelling house. Thus, the arrangements deviated from each other with respect to indoor humidity load. Few studies that focus on cavities have been previously published. Therefore, the evaluation of the results is challenging.

The results show that in HI-structures, the temperature in the ventilation cavity is very close to, but slightly above, outdoor temperature. This is especially important during the cold season when the outdoor weather and the cavity conditions are most favorable for mold growth. Higher cavity temperature decreases the $\mathrm{RH}$ in the cavity and the probability for mold growth. The results for winter apply also to north-facing walls, since in winter the solar irradiance in Finland is zero and the warming of the cavity is based on the heat flux through the structure.
In the cavities of HI-walls, the measured $\mathrm{RH}$ is a little higher than in the BL structure. This does not roof, (1) $1 / 1 / 0.5,(2) 2 / 2 / 0.25$, measured climate

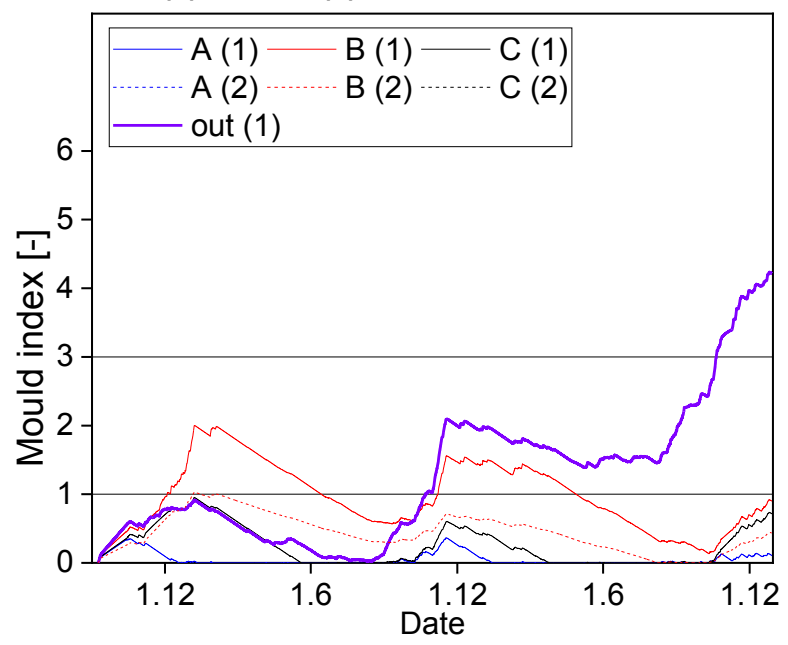

Fig. 17. Calculated MI values in the examined roof structure and in the Helsinki climate.

$$
\text { roof, (1) 1/1/0.5, (2) 2/2/0.25, A2_2050-climate }
$$

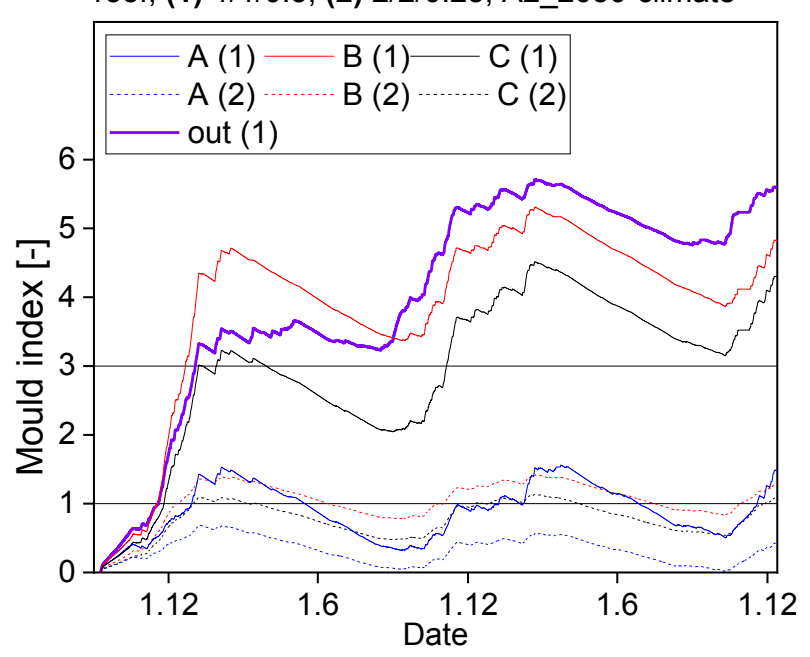

Fig. 18. Calculated MI values in the examined roof structure and in the Helsinki climate with estimated conditions in the year 2050 based on [16].

present severe moisture risks in HI-walls in the current weather conditions regardless of the vapor barrier type that is used. The study included a very vapor-tight structure, a conventional structure with PE-foil and a modern structure with a moisture-adaptive vapor barrier. The hygroscopicity of the wind barrier layer had a low impact on the cavity moisture levels that might result from the already high moisture buffering capacity of the wooden cladding.

However, a modern HI-roof with an adaptive vapor barrier might suffer from slight mold growth in the cavity. The risk is higher if the envelope of the building is completed during humid weather and the indoor humidity stays high for a while. In addition, in roof structures, the conditions in the cavity might be worse than in walls since the cavity temperature is even closer to the outdoor temperature due to the lower U-value. The cavity temperature is further decreased by the long-wave radiation loss typical of roof structures. On the other 
hand, the pressure difference in roof structures is generally directed upward; hence, slight mold growth in the cavity might not result in indoor air problems.

In the cavity of an HI-wall, the most probable location for mold growth is the bottom of the cavity. The MI analysis and the visual observations showed that minor mold growth is possible in the bottom of the cavity in the current climate, and the risks may increase if the future climate is warmer and more humid, which also rises the moisture risks of HI-roofs. However, the mold growth in the cavities of HI-walls and HI-roofs can be limited to an acceptable level by, for example, using materials that are more resistant to mold.

The observations in this article emphasize the importance of studying the moisture safety of the ventilation cavity in HI-structures. The research methods should account for the locality in the hygrothermal conditions along the cavity. The numerical models utilizing air change rate in a closed air space to model the cavity ventilation may not be accurate enough. Instead, it is recommended to model the airflow in the cavity and to include the convective terms in the heat and moisture equations. However, simulations such as these are challenging to perform, as it was observed that the cavity conditions in ventilated structures change rapidly. Therefore, experimental studies, such as those described in this article, are necessary for validating the numerical models. Building materials applicable to the ventilation cavities in HI-structures should be studied more, as sensitive materials like gypsum boards and wooden materials need careful planning and execution. Materials in HI-roof structures are exposed to the most challenging conditions. Finally, the influence of mold growth inside the cavity on indoor air quality should be further evaluated.

\section{References}

1. N. T. Berg, Moisture Safety in Highly Insulated Wood-Frame Wall Constructions. M.Sc-thesis (Norwegian University of Science and Technology, Trondheim, 2017)

2. J. Vinha, A. Laukkarinen, Effects of climate change and increased thermal insulation on the hygric performance of envelope structures and energy consumption of buildings (in Finnish). Research report 159 (Tampere University of Technology, 2013)

3. P. Pihelo, H. Kikkas, Enrgy. Proced. 96, 685 (2016)

4. K. Viljanen, X. Lu., Appl. Sci. 9, 6 (2019)

5. T. Jokela, The building physical behaviour of wood frame external walls with wind barrier gypsum boards (in Finnish). M.Sc-thesis (Tampere university of technology, 2018)

6. T. M. Trainor, J. Smegal, J. Straube, A. Parekh., Thermal Performance of the Exterior Envelopes of Whole Buildings XIII, 504 (2016)

7. L. Wang, H. Ge., Build. Environ. 146, 12 (2018)
8. V. Lappalainen, E. Sohlberg, H. Järnström, J. Laamanen, H. Viitanen, P. Pasanen., Enrgy. Proced. 78, 1212 (2015)

9. T. Ojanen, J. Hyvärinen, Statement on the effects of improving energy efficiency of structures on the hygric behaviour of structures (in Finnish). Research report VTT-S-10816-08 (Teknologian tutkimuskeskus VTT Oy, 2008)

10. K. Liersch, Ventilated roof and wall structures. Volume 1 - curtain walls. Building physical fundamentals of heat and moisture protection (in German) (Bauverlag, Germany, 1981)

11. Material library DB 24.78.01 in program WUFI (Fraunhofer IBP, Germany, 2013)

12. J. Falk, K. Sandin., Build. Environ. 59, 164 (2013)

13. J. Langmans, T. Z. Desta, L. Alderweireldt, S. Roels., Build. Environ. 95, 1 (2016)

14. L. E. Nevander, B. Elmarsson, Fukthandbok: Praktik Och Teori (Svensk byggtjänst, Solna, 2006)

15. S. Koponen, S. Peltola, P. Tukiainen, Effective Moisture Capacity of Wood in Building Structures: A Wooden Building With Comfortable Temperature and Humidity Conditions (Helsinki University of Technology, Otamedia, Espoo, 2004)

16. K. Ruosteenoja, K. Jylhä, H. Mäkelä, R. Hyvönen, P. Pirinen, I. Lehtonen, Weather data from the building physical test years in the observed and estimated future climate. The results of the REFI-B project (in Finnish). Reports 2013:1 (Finnish Meteorological Institute, Unigrafia, Helsinki, 2013)

17. K. Lähdesmäki, J. Vinha., Proc. of the 8th Symposium on Building Physics in the Nordic Countries 2, 935 (2008)

18. H. Viitanen, J. Vinha., Proc. of the 8th Symposium on Building Physics in the Nordic Countries 2, 927 (2008)

19. E. Tuominen, A. Ruusala, A. Laukkarinen, S. Pätsi, A.-M. Pessi, J. Vinha., Rakennusfysiikka 2019. Uusimmat tutkimustulokset ja hyvät käytännön ratkaisut 2, 517 (2019) 